\title{
Regulation of epithelial-mesenchymal transition through epigenetic and post- translational modifications
}

\author{
Silvia Juliana Serrano-Gomez ${ }^{1,2}$, Mazvita Maziveyi ${ }^{1}$ and Suresh K. Alahari ${ }^{{ }^{*}}$
}

\begin{abstract}
The epithelial to mesenchymal transition (EMT) is a biological process in which a non-motile epithelial cell changes to a mesenchymal phenotype with invasive capacities. This phenomenon has been well documented in multiple biological processes including embryogenesis, fibrosis, tumor progression and metastasis. The hallmark of EMT is the loss of epithelial surface markers, most notably E-cadherin, and the acquisition of mesenchymal markers including vimentin and $\mathrm{N}$-cadherin. The downregulation of E-cadherin during EMT can be mediated by its transcriptional repression through the binding of EMT transcription factors (EMT-TFs) such as SNAIL, SLUG and TWIST to E-boxes present in the E-cadherin promoter. Additionally, EMT-TFs can also cooperate with several enzymes to repress the expression of E-cadherin and regulate EMT at the epigenetic and post- translational level. In this review, we will focus on epigenetic and post- translational modifications that are important in EMT. In addition, we will provide an overview of the various therapeutic approaches currently being investigated to undermine EMT and hence, the metastatic progression of cancer as well.
\end{abstract}

Keywords: Cancer, Metastasis, Epigenetic, Methylation, Therapy

\section{Background}

Epithelial-mesenchymal transition (EMT) is a biological process in which non-motile, polarized epithelial cells undergo a series of biochemical alterations, becoming motile non-polarized mesenchymal cells with invasive capacity, resistance to apoptosis and altered biosynthesis of extracellular matrix (ECM) components. Epithelial and mesenchymal cells differ in their morphology and tissue organization. In a typical epithelium, cells are organized either as a single layer or in multi-layered sheets. In the latter case, structure is maintained through cell-cell interactions including tight junctions, gap junctions, cadherin based adherent junctions, desmosomes and ECM interactions $[1,2]$. These junctions and interactions impede the movement of individual cells within the epithelial monolayer [3, 4]. Mesenchymal cells rarely establish tight junctions with surrounding cells and are embedded inside the extracellular matrix [5].

\footnotetext{
* Correspondence: salaha@lsuhsc.edu

'Department of Biochemistry and Molecular Biology, LSUHSC School of Medicine, New Orleans, LA 70112, USA

Full list of author information is available at the end of the article
}

Cytoskeletal changes and cell signaling pathways are altered as a cell undergoes EMT. Processes known to contribute to EMT include the activation of transcription factors (TFs) such as SNAIL, SLUG and TWIST, altered expression of specific cell-surface proteins, reorganization and expression of cytoskeletal proteins, production of ECM-degrading enzymes, and changes in the expression of specific microRNAs [6,7]. EMT is initiated following the dissolution of tight junctions resulting in the loss of apical-basal cell polarity [8,9]. Other types of cell junctions are disassembled as well, such as gap and adherent junctions, leading to the loss of basement membrane integrity. The cytoskeleton also undergoes characteristic reorganization such as increased allocation of actin into stress fiber formation and the replacement of cytokeratin intermediate filaments by vimentin. These alterations enable the transition into a spindle-shaped cell morphology from a cuboidal/columnar precursor, correspond with an increased ability to invade surround tissue [10-12]. A cell is considered to have undergone EMT following the loss of epithelial marker expression in tandem with the development of 
mesenchymal marker expression. Key epithelial markers lost include E-cadherin (CHD1), Mucin-1, Cytokeratins (such as CK19, CK18, CK8), Occludin and Desmoplakin. Oppositely, markers gained during the process include $\mathrm{N}$-cadherin, Vimentin, Smooth Muscle Actin ( $\alpha \mathrm{SMA})$, Fibronectin, and Vitronectin, which together comprise the key mesenchymal markers [6, 13-16]. In addition numerous proteins not located on the cell surface also undergo key changes in localization. $\beta$-catenin, a component of the cadherin complex is one such example. During EMT, $\beta$-catenin dissociates from the cadherin complex and is translocated into the nucleus where it behaves as a transcription factor, regulating the expression of several genes in key pathways such as Wnt signaling. Importantly, the changes observed in cells to revert back to a epithelial-like phenotype upon arrival at a suitable location to colonize, a process prudently entitled mesenchymal to epithelial transition (MET) [5].

EMT has been classified into three categories: type I, type II and type III $[17,18]$. Type I occurs during embryogenesis where cells need to migrate to adjacent tissues in order to form new organs and tissues [5]. Type II is associated with the wound healing, whereby fibroblasts repair or rebuild tissues [6]. Unlike types I and II which perform necessary physiologic functions, type III is a pathophysiologic adaptation of the process, and is closely associated with progression of neoplasia occurring in cells containing certain epigenetic and genetic changes $[4,19]$. It is currently theorized that exploitation of the normal EMT signaling pathways provides the molecular genetic basis for how neoplastic (but differentiated) cells can shed their epithelial characteristics and acquire migratory properties. Having undergone such a change, the cells are subsequently able to invade tissues surrounding the primary tumor, extravasate into lymphatics or blood vessels, travel to distant sites through the circulation, and ultimately colonize a metastatic niche $[18,20]$. It is important to highlight that oncogenic EMT is a transient process that may function in a paracrine fashion and is followed by MET once the tumor cells reach the metastatic site [21].

The EMT program is activated by multiple signaling pathways as well as several epigenetic and post-translational modifications such as methylation, acetylation, phosphorylation, glycosylation, hydroxylation and SUMOylation. Epigenetic modifications including modification of histone protein tails, and DNA promoter regions, play a key role in regulating gene expression by defining whether chromatin at a given genomic locus will be transcriptionally active or inactive [22]. Post translational modifications are covalent modifications that occur after transcript has been translated into protein [23]. Improving our understanding of how these modifications function in the regulation of EMT is of crucial importance, and likely instance where novel therapeutics might be developed to better treat diseases such as cancer [24]. Since the EMT program is regulated dually by epigenetic and post translational modifications, we will focus closely on these two mechanisms as they pertain to EMT in this review. In addition, we will provide a current overview of the various therapeutic approaches currently being investigated to undermine EMT.

\section{E-cadherin as a key epithelial marker}

The CDH1 gene is located on chromosome 16q22.1 and codes for the subtype of cadherin protein expressed by epithelial cells (E-cadherin). Functionally, E-cadherin behaves as a tumor suppressor gene and plays diverse roles in regulating cell polarity, differentiation, migration and stem cell-like properties. In the context of cell polarity, E-cadherin binds to adjacent cells creating an intercellular complex that forms epithelial barriers. The extracellular portion of E-cadherin binds to cadherins on an adjacent cell creating a bridge between the cytoskeletons of contiguous cells. The intracellular domain of E-cadherin interacts with $\beta$-catenin, which itself is linked actin filaments within the cells via a linker protein called $\alpha$-catenin [25-27].

Down-regulation or inactivation of $C D H 1$ has been frequently observed during tumor cell progression, and several mechanisms have been proposed [28]. These include germline mutations $[29,30]$, promoter hypermethylation [31, 32] and upregulation of E-cadherin transcriptional repressors [10], alternatively known as EMT transcription factors (EMT-TFs). Transcription factors such as SNAIL, SLUG, ZEB1, and ZEB2/SIP1 are considered direct repressors of E-cadherin as they bind to E-boxes present on the CDH1 promoter [10, 33, 34]. Indirect repressors include bHLH proteins (TWIST1 and TWIST2), homeobox proteins (GSC and SIX1), the bHLH factor E2.2 and the forkhead-box protein FOXC2 [2, 10]. Additionally, while the TWIST proteins are commonly recognized as an indirect repressors of $C D H 1$, they can also bind directly on E-boxes 2 and 3 present on the $C D H 1$ promoter to repress its expression [35].

\section{Epigenetic modifications during EMT}

Epigenetic modifications allow for regulation of gene activity and expression without altering the DNA sequence. Such changes include methylation of cytosine residues in CpG dinucleotides in the DNA; and histone modifications at N-terminal tails including acetylation, methylation, phosphorylation and ubiquitination [36, 37]. DNA methylation is a well-studied epigenetic event associated with transcriptional silencing resulting from disrupted binding affinity between gene promoters and their cognate TFs. Modification of histones on the other hand alters gene expression 
by reshaping the anatomy of the nearby chromatin resulting in alterations in the ability of transcriptional machinery to access genes within the region [36]. Below, we will discuss each of these epigenetic modifications in further detail.

\section{DNA methylation}

DNA methylation is one of the fundamental epigenetic modifications in mammals. It occurs at the 5-position of cytosine $(5 \mathrm{mC})$ in $\mathrm{CpG}$ dinucleotides and is catalyzed by DNA methyltransferases (DNMTs) [38, 39]. The DNMT family is composed of four members: DNMT1, DNMT3A, DNMT3B, and DNMT3L. DNMT1 maintains DNA methylation during DNA replication, while DNMT3a and DNMT3b regulate de novo DNA methylation primarily during embryonic development. The inactivation of $C D H 1$ by hypermethylation is a common event in multiple human carcinomas including breast, bladder, lung, liver, gastric and prostate [32, 40-42]. Additionally, promoter hypermethylation of the $\mathrm{CDH} 1$ gene is positively associated with EMT in breast cancer cell lines, corresponding with the increased potential for invasion and metastasis observed in these cells [43].

In murine cells, oncogenic Ras has been shown to induce EMT in cooperation with certain serum factors [44]. Dumont and colleagues [45] worked with a model of immortalized Human Mammary Epithelial cells (HMEC) with repressed p16INK4A (vHMEC)-expressing oncogenic Ras (vHMEC-ras) and showed that these cells change morphology and became motile when cultured in serum-rich media. Moreover, they reported changes in the methylation status of several genes including $C D H 1$ promoter as well as ESR1 (which codes for estrogen receptor) and TWIST in cells with a mesenchymal phenotype that were exposed to $10 \%$ serum but not in cells with the epithelial phenotype.

Several transcriptional factors including ZEB1, SNAIL and TWIST regulate CDH1 expression (Fig. 1). ZEB1 is a transcription factor that plays important roles in

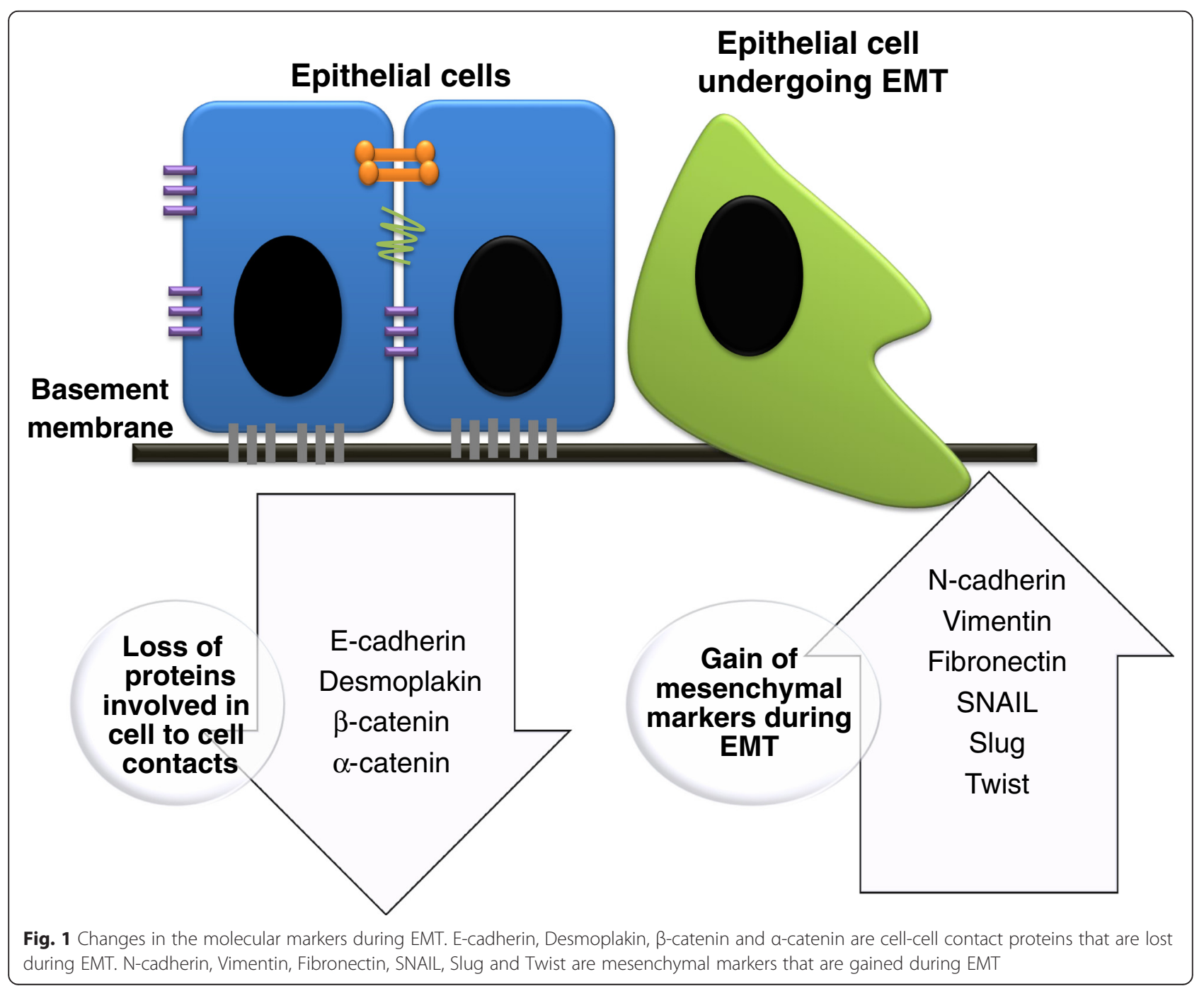


embryogenesis and cell differentiation [46]. ZEB1 represses $C D H 1$ transcription by its binding to two E-box sequences in the promoter. ZEB1 can also regulate CDH1 expression at the epigenetic level. Basal-like breast cancer (BLBC) is a breast cancer subtype enriched with expression of mesenchymal genes and reduced expression of epithelial genes including Ecadherin [47]. Downregulation of CDH1 in BLBC is mediated by ZEB1, which recruits DNMT1 to the $C D H 1$ promoter to maintain the methylation status in the promoter [38]. These results suggest that ZEB1 acts as a transcriptional repressor and an epigenetic modulator to induce EMT in breast cancer. Although the hypermethylation of $C D H 1$ has been well-associated with EMT, McDonald and colleagues showed that the DNA methylation was unchanged during EMT in a model of mouse hepatocytes treated with TGF- $\beta$ [48]. It is important to note that the mechanisms leading to EMT could be different in normal compared to cancer cells. In fact, Dumont and colleagues [45] suggested that TGF- $\beta$ signaling and oncogenic stress induce EMT in human cells.

DNA methylation inhibitors such as 5-aza-2' -deoxycytidine (5-aza-CdR) have been found to function as anticancer agents in light of their ability to reactivate tumor suppressor gene expression [49]. However, Ateeq and colleagues [50] have hypothesized that such demethylating agents might also increase the risk of tumor metastasis by inadvertently activating genes involved in invasion and metastasis. They tested the DNA methylation in a set of genes involved in metastasis, angiogenesis and cell cycle regulation as well as in the tumor suppressor gene RASSF1A after treatment with 5-aza-CdR in noninvasive human breast cancer cells MCF7 and ZR-75-1. They found that although treatment with 5 -aza-CdR increased the expression level of RASSF1A, it also increased the expression of genes involved in metastasis, such as UPA, SNCG, and CXCR4 [50, 51]. The mechanism responsible for the increase in the expression of those genes was attributed to demethylation at their regulatory regions. Such findings highlight the fundamental importance of DNA methylation in contribution to the activation of prometastatic genes, and consequently, EMT.

\section{Histone modifications Methylation}

SNAIL is a zinc finger transcription factor that regulates EMT during development of the mesoderm and neural crest [52]. In breast cancer, the expression of SNAI1 has been shown to be upregulated in recurrent tumors and in addition, is associated with metastasis and decreased relapse-free survival [52]. Similar to ZEB1, SNAIL suppresses the transcription of $C D H 1$ by binding to E-boxes in the $C D H 1$ promoter [53]. It can also cooperate with histone methyltransferases (HMT) and DNMTs to modulate the expression of $\mathrm{CDH} 1$ (Table 1) [37].

KDM6B in EMT: KDM6B (also known as JMJD3) is an $\alpha$-ketoglutarate dependent demethylase containing a conserved Jumonji C (JmjC) domain. This enzyme is responsible for the demethylation of di- and trimethyllysine $27(\mathrm{H} 3 \mathrm{~K} 27 \mathrm{~m} 2 / 3)$ on histone $\mathrm{H} 3$ (Table 1$)$. $\mathrm{H} 3 \mathrm{~K} 27 \mathrm{~m} 2 / 3$ is an epigenetic modification associated with gene silencing $[54,55]$. It has been reported that KDM6B expression is higher in metastatic prostate cancer [56]. It is also highly expressed in invasive breast carcinomas compared to normal tissues. Moreover, during TGF $\beta$-induced EMT, TGF- $\beta$ activates KDM6B which then demethylates H3K27m3 at SNAI1 promoter. This epigenetic modification activates the transcription of SNAI1. This suggests a role for KDM6B during tumor invasion which was demonstrated in MDA-MB-231 cells [57].

MMSET in EMT: TWIST is a transcription factor that regulates cell migration and tissue reorganization during early embryogenesis but also plays an important role in EMT and tumor metastasis [58, 59]. TWIST induces the down-regulation of E-cadherin and increased expression of mesenchymal markers such as Fibronectin, Vimentin, aSMA, and N-cadherin [60]. The overexpression of TWIST has been associated with poor prognosis in human cancers [58, 60, 61]. One mechanism by which TWIST induces EMT is through its interaction with a HMT. MMSET (also known as WHSC1 or NSD2) is a HMT that was first identified as a candidate gene for Wolf-Hirschhorn Syndrome (WHS). MMSET can di- or trimethylate histone $\mathrm{H} 3$ at lysine 36 (H3K36) (Table 1) $[25,62]$. In solid tumors, MMSET is overexpressed and associated with poor prognosis [63]. MMSET binds to the TWIST promoter and increases its methylation at H3K36m2. This change results in TWIST activation, which contributes to prostate cancer progression.

\begin{tabular}{lll}
\multicolumn{2}{l}{ Table 1 Key Histone Methyltransferases in EMT } & \\
\hline HMT & Histone & Promoter \\
\hline KDM6B & H3K27m3 & SNAl1 \\
MMSET & H3K36m2 & TWIST \\
LSD1 & H3K4m2 & CDH1 \\
Suv39H1 & H3K9m3 & $\mathrm{CDH1}$ \\
SET8 & H4K2Om1 & $\mathrm{CDH1}$ \\
& & $\mathrm{CDH} 2$ \\
G9a & H3K9m1/2 & $\mathrm{CDH1}$
\end{tabular}

KDM6B demethylates H3K27 at the SNAl1 promoter. MMSET can di- or trimethylate $\mathrm{H} 3 \mathrm{~K} 36$ at the TWIST promoter. LSD1 methylates H3K4m2 on $\mathrm{CDH} 1$. Suv39H1 can trimethylate $\mathrm{H} 3 \mathrm{~K} 9$ on the $\mathrm{CDH} 1$ promoter. SET8 methylates $\mathrm{H} 4 \mathrm{~K} 20$ on the $\mathrm{CDH} 1$ and $\mathrm{CDH} 2$ promoters. $\mathrm{G} 9 \mathrm{a}$ is responsible for mono and dimethylation of $\mathrm{H} 3 \mathrm{~K} 9$ 
LSD1 in EMT: Several histone demethylases regulate E-cadherin expression. The histone demethylase LSD1 (also known as KDM1A and AOF2) plays an important role in EMT [64]. It has been shown that SNAIL interacts with LSD1 through its SNAG (SNAI1/GF) domain and recruits LSD1 to CDH1 promoter. As a consequence, methyl groups on lysine 4 of histone $\mathrm{H} 3$ will be removed (H3K4m2) (Table 1). The demethylation suppresses the expression of $C D H 1$ and enhances cell invasion. This mechanism suggests that LSD1 could be a good target for a new therapeutic modality. Another proposed therapeutic approach could be to construct peptides that mimic the structure of the SNAG domain of SNAIL to inhibit its function during EMT and cancer progression $[64,65]$.

SUV39H1 in EMT: Suv39H1 (suppressor of variegation 3-9 homolog 1) is a histone methyltransferase responsible for the trimethylation of histone $\mathrm{H} 3$ at lysine $\mathrm{K} 9$ $(\mathrm{H} 3 \mathrm{~K} 9 \mathrm{~m} 3)$ in the $C D H 1$ promoter (Table 1$)$. The mechanism responsible for this post transcriptional modification is through the interaction of SNAIL with Suv39H1. This interaction leads to the recruitment of Suv39H1 to the $C D H 1$ promoter to repress its transcription. The suppression of Suv39H1 could be a good therapeutic approach to rescue $C D H 1$ expression in cancers where the DNA methylation levels are high, such as in BLBC [66].

SET8 in EMT: SET8 (also known as PR-Set7/9, SETD8 or KMT5A) is a HMT of the SET domain-containing methyltransferase family. SET8 methylates lysine 20 of histone H4 (H4K20), and regulates transcription both positively as well as negatively (Table 1) [67]. SET8 mediates the transcriptional activation of WNT target genes $[59,68]$ and regulates the S-phase progression of the cell cycle [69]. In EMT, SET8 has dual functions; activation of $\mathrm{N}$-cadherin and repression of $\mathrm{CDH} 1$ expression. The physical interaction between SET8 and TWIST promotes the recruitment of SET8 to the $\mathrm{N}$-cadherin promoter and induces H4K20 methylation (H4K20m1). This modification results in activation of $\mathrm{N}$-cadherin expression. In contrast, $\mathrm{H} 4 \mathrm{~K} 20 \mathrm{~m} 1$ methylation of the $C D H 1$ promoter represses $C D H 1$ expression suggesting that methylation has two distinct functions.

G9A in EMT: G9a is a HMT responsible for mono and dimethylation of histone $\mathrm{H} 3$ at lysine $\mathrm{K} 9(\mathrm{H} 3 \mathrm{~K} 9 \mathrm{~m} 1$ and $\mathrm{H} 3 \mathrm{~K} 9 \mathrm{~m} 2$ ) (Table 1). Methylation at this residue is associated with repression of transcription [37]. It has been shown that the c-terminal domain of SNAIL interacts with ankyrin repeat and SET domains of G9a, and recruits G9a and DNMTs (DNMT1, DNMT3a and DNMT3b) to the $C D H 1$ promoter resulting in its methylation. The knockout of G9a restored $\mathrm{CDH1}$ expression and results in the inhibition of cell migration and invasion in a model of breast cancer [70]. Although DNMT1 can modulate the expression of $\mathrm{CDH} 1$ through increasing promoter methylation levels, it could govern expression of CDH1 in a methylation-independent manner as well. DNMT1 can interact with SNAIL to prevent its interaction with the $C D H 1$ promoter leading to full expression of $C D H 1$ [71].

When considered together, the examples discussed above provide the current framework for the epigenetic regulation of EMT-TFs. This type of regulation is responsible for the key TFs which lead to the suppression of E-cadherin- a fundamental step in the initiation of EMT program and thus is of paramount importance to cells undergoing EMT. Designing drugs to target the components of this process is a budding field of cancer pharmacotherapy, but is complicated by the variable effects which histone methylation can have on gene expression (e.g., methylation at $\mathrm{H} 3 \mathrm{~K} 36 \mathrm{~m} 2$ activates TWIST gene expression, while methylation at H3K27 inactivates SNAIL gene expression). Thus, future treatments will need to get target specific methyltransferase or demethyltransferases in order to be effective, rather than simply altering histone methylation in a unilateral fashion.

In the context of EMT, hypermethylation of E-cadherin is an epigenetic modification associated with the invasive capacity of cancer cells and occurs through the interactions of EMT-TF with several HMTs and DNMTs. The interactions among these complexes can either repress the expression of $C D H 1$, inducing a mesenchymal state, or repress the expression of the EMT-TF, thereby maintaining an epithelial state. Currently, several DNA methylation inhibitors are approved by the US Food and Drug Administration (FDA). One such inhibitor, 5Azacytidine, is well known to have good efficacy in treating myelodysplastic syndromes [72, 73]. The identification of these epigenetic markers within a tumor would be helpful to develop new therapeutic approaches by targeting enzymes that modulate EMT in cancers.

\section{Acetylation}

Histone acetylation and deacetylation play important roles in the regulation of transcription [74]. Histone acetylation is catalyzed by Histone Acetyl Transferases (HATs), an event which is usually associated with transcriptionally active chromatin. As a result of acetylation, positively charged lysines are neutralized which increases accessibility to DNA. On the other hand, histone deacetylases (HDACs) catalyze the removal of the acetyl residues in the chromatin of inactive regions [31, 74, 75]. HATs and HDACs are usually part of multi-protein complexes composed of co-activators or co-repressors that are recruited to specific DNA sequences to determine the acetylation status [31]. Multiple HDACs have 
been identified in mammals and are grouped according to their homology to deacetylases in yeast. HDAC1 and HDAC2 are class I enzymes and have been found to be overexpressed in some cancers [76]. HDAC1 is highly expressed in hepatocellular carcinoma, breast, and liver, prostate, gastric and colon cancer; and HDAC2 is overexpressed in colorectal, cervical and gastric cancer [77, 78].

Histone deacetylation is at least one mechanism by which the aforementioned SNAIL represses E-cadherin expression. SNAIL directly interacts with E-cadherin promoter and recruits HDAC1, HDAC2 and the corepressor $\operatorname{Sin} 3 \mathrm{~A}$ to the $C D H 1$ promoter to silence its expression by deacetylation of histones $\mathrm{H} 3$ and $\mathrm{H} 4$. This effect was abolished by treatment with the HDAC inhibitor Trichostatin A (TSA) [31]. HDAC1 is also required for TGF $\beta 1$-induced EMT in hepatocytes and frequently overexpressed in hepatocellular carcinoma (HCC), suggesting a strong connection between HDAC1 and the invasive properties of HCC. HDAC1 has been shown to repress the epithelial genes such as $C D H 1$ and $Z O-1$ [79]. In pancreatic cancer, downregulation of E-cadherin occurs through ZEB1, which recruits HDAC1 and HDAC2 to the CDH1 promoter to silence its expression [80]. In contrast, in ZEB1 knockdown cells, HDACs cannot be recruited, and as a consequence, E-cadherin expression is induced in such cases, implicating a significant role of HDAC in EMT.

Also, E-cadherin expression is regulated by SMAR1 (Scaffold/Matrix attachment region-binding protein) which forms a complex with HDAC1 and binds to the SLUG promoter. This results in the repression of the transcription of SLUG, and thus restores E-cadherin expression [81]. As described above, TWIST is considered an indirect repressor of E-cadherin. The Mi2/nucleosome remodeling and deacetylase (Mi2/NuRD) complex contains multiple proteins that have activities similar to histone deacetylase and chromatin-remodeling ATPase. TWIST can interact with proteins in the Mi $2 / \mathrm{NuRD} /$ MTA2 complex and recruit this complex to the $C D H 1$ promoter that results in the repression of E-cadherin expression [82].

Another family of proteins that regulate acetylation is the sirtuins. Sirtuins are class III histone deacetylases that use nicotinamide adenine dinucleotide (NAD+) to mediate the deacetylation of histone and non-histone substrates. Thus, sirtuin activity is regulated by the intercellular $[\mathrm{NAD}+] /[\mathrm{NADH}]$ ratio $[74,83]$. The sirtuin family of proteins is composed of seven members (SIRT1-7). SIRT1, 2, 3 and 5 target proteins in the nucleus, cytoplasm and mitochondria for acetylation, while SIRT 4 and 6 regulate ADP ribosylation [84]. SIRT1 deacetylates histone $\mathrm{H} 4$ lysine 16 (H4K16) as well as histone H3 lysine 9 (H3K9) and histone H3 at lysine 14 (H3K14). Some reports indicate that SIRT1 may provide genetic stability and suppress tumor formation [85]. In contrast, other studies indicate that SIRT1 levels are high in cancer samples and this is associated with poor prognosis and metastasis [86-88]. Thus the exact role of SIRT1 in cancer is very controversial. An example of how SIRT1 acts as a negative regulator of EMT is in oral squamous cell carcinoma (OSCC). The expression of SIRT1 in OSCC decreases TGF- $\beta$-mediated cell migration and metastasis. This occurs due to high levels of SIRT1 expression and leads to the deacetylation of SMAD4, a downstream target of TGF- $\beta$ which suppresses the expression of MMP7. Downregulation of SIRT1 leads to SMAD4 hyperacetylation and MMP7 hyperactivation that results in the degradation of E-cadherin, the release of $\beta$-catenin from cell junctions and translocation to the nucleus to promote metastasis in OSCC cells [89]. On the other hand, in prostate cancer, SIRT1 induces EMT [90]. The mechanism is through ZEB1, which recruits SIRT1 to the $C D H 1$ promoter to deacetylate histone H3. As a consequence, the RNA polymerase binding and CDH1 transcription are reduced. These results suggest that SIRT1 may be a good therapeutic target for prostate cancer among others [91].

\section{Interplay between HDAC and HMT to regulate EMT}

Hypoxia is a microenvironmental condition known to promote tumor progression through the stabilization of Hypoxia Inducible Factor-1 (HIF-1). HIF- $1 \alpha$ activates genes involved in cellular processes such as angiogenesis, invasion and EMT $[24,58]$. Under hypoxic condition, different chromatin modifiers regulate EMT [92]. WDR5 is a WD40 repeat protein and a HMT that is essential for histone H3 lysine 4 (H3K4) methylation [92, 93]. HIF- $1 \alpha$ activates the expression of HDAC3 that deacetylates H3K4 on both mesenchymal genes (Vimentin and $\mathrm{N}$-cadherin) and epithelial genes (E-cadherin and Plakoglobin). To modulate EMT, HDAC3 additionally recruits the WDR5/HMT complex to mesenchymal promoters and increases the methylation levels of H3K4m2 to promote gene activation and EMT. The knockdown of WDR5 abolishes the activation of mesenchymal genes during hypoxia [92]. These results suggest that hypoxiainduced EMT is regulated by interplay between histone deacetylases (HDAC3) and histone methyltransferases complexes.

HDACs mediate epigenetic mechanisms with important roles in cell cycle regulation, cell proliferation and differentiation [94]. The activity of HDACs has also been associated with the development and progression of fibrotic disorders [95], as well as cancer, and thus it is important to explore potential applications of HDAC inhibitors to inhibit EMT. However, the role of certain HDACs is still controversial, which hinders the development of a viable therapeutic option [81]. However, 
therapeutic use of HDAC inhibitors such as SAHA (suberoylanilide hydroxamid acid), valproic acid (VPA) and trichostatin A (TSA) has been tested in several models of cancer showing promising results [96]. For example, in triple negative breast cancer, Panobinostat an inhibitor of HDAC class I, II and IV, inhibits proliferation as well as increases the expression of E-cadherin [97]. In summary, complete understanding of histone acetylation in EMT will lead to more effective cancer treatments.

\section{Post-translational modifications during EMT}

Post- translational modifications (PTMs) are covalent modifications that occur after RNA is translated into protein [23]. These covalent modifications include the addition of a modifying chemical group or the addition of another small protein to one or more residues of the target protein [98]. PTM can either occur on a single residue within the protein or on multiple residues undergoing the same or different modification [99]. In this review we will focus on hydroxylation, phosphorylation, SUMOylation and glycosylation (Table 2).

\section{Hydroxylation}

Hydroxylation is a post-translational modification that occurs in proline residues [100]. The HIF-prolyl hydroxylases (HPHs) also known as prolyl hydroxylase domain (PHD) proteins are enzymes that use oxygen and 2-oxoglutarate (2-OG) as co-substrates, and iron and ascorbate as cofactors. PHDs sense the cytosolic concentration of oxygen and as a result they regulate HIF- $1 \alpha$. PDHs hydroxylate HIF- $1 \alpha$ at two proline residues (Pro402 and Pro564) located in the oxygen-dependent degradation domain (ODDD) [100].

HIF- $1 \alpha$ activates genes involved in cellular processes such as angiogenesis, invasion and EMT [24]. Under

Table 2 Post - Translational Events in EMT.

\begin{tabular}{ll}
\hline Post- translational event & Modified protein \\
\hline Hydoxylation & HIF1A \\
Phosphorylation & SNAIL \\
& Par6 \\
SUMOylation & FoxM1 \\
& TFAP2C \\
Glycosylation & SIP1
\end{tabular}

Hydroxylated HIF-1a is stabilized and promotes EMT by decreasing epithelial markers such as E-cadherin and gaining mesenchymal markers such as a-SMA and FSP1. Phosphorylation of SNAIL mediated either by PKD1 or GSK-3B results in SNAIL degradation by the proteasome. Phosphorylated Par6 interacts with the E3-ubiquitin ligase Smurf-1 that targets RhoA for degradation, leading to the disassembly of tight junctions. FoxM1 SUMOylation leads to repression of miR-200 tumor suppressors that enhance the expression of E-cadherin and suppress the expression of ZEB1 and ZEB2. TFAP2C undergoes SUMOylation that blocks its ability to induce the expression of luminal genes and helps it to maintain basal like features. SIP1 SUMOylation leads to the recruitment of the co-repressor $\mathrm{CtBP}$ which maintains $\mathrm{CDH1}$ expression. Lastly, SNAIL is glycosylated under hyperglycemic conditions to promote EMT normoxia, HIF- $1 \alpha$ is hydroxylated by a family of oxygen dependent prolyl hydroxylases (PHD1-3). The HIF-1 $\alpha$ associated prolyl hydroxylase PHD2 is an important cellular oxygen sensor that regulates HIF-1 $\alpha$ degradation under normoxia [101]. The hydroxylated HIF-1 $\alpha$ is recognized by a protein complex consists of the tumor suppressor Von Hippel-Landau protein, Elongin B, Elongin C, and Cullin 2 and possesses E3 ubiquitin ligase activity, which targets HIF-1 $\alpha$ for polyubiquitination and degradation. In contrast, under hypoxic conditions, prolyl hydroxylation is inhibited leading to HIF- $1 \alpha$ stabilization [101]. There are elements in the tumor microenvironment such as TGF $\beta$ that influence the activity of HIF- $1 \alpha$ under normoxia. TGF $\beta$ decreases PHD2 mRNA and protein levels. As a consequence, hydroxylation of the ODDD domain of HIF- $1 \alpha$ goes down, which results in an increase of HIF-1 stability [101] (Fig. 2). TGF $\beta$ decreases PHD2 expression in a SMAD2/3 dependent manner. As a result of PHD2 decreased expression, HIF- $1 \alpha$ is stabilized and promotes EMT by decreasing epithelial markers such as E-cadherin and gaining mesenchymal markers such as $\alpha$-SMA and Fibroblast Specific Protein 1 (FSP-1). TWIST is a downstream target of HIF-1 $\alpha$ and has a hypoxia-response element (HRE) at the promoter region. Once HIF-1 $\alpha$ is stabilized, it binds to the HRE of TWIST and promotes EMT. This suggests that one of the mechanisms by which hypoxia induces EMT is through the direct activation of TWIST (Fig. 2).

\section{Phosphorylation}

Protein phosphorylation is the most common post translational modification and is essential for the regulation of multiple molecular pathways involved in processes such as metabolism, transcription, differentiation and apoptosis. Phosphorylation is catalyzed by enzymes called Protein Kinases (PK) that catalyze the transfer of $\gamma$-phosphate of ATP to serine, threonine or tyrosine residues on target proteins. Protein Phosphatases (PP) catalyze the reverse process [102-104].

Phosphorylation is another post- translational modification known to control SNAIL [105]. GSK-3 $\beta$, a wellknown kinase involved in many signaling pathways, phosphorylates SNAIL at two consecutive motifs that control its ubiquitination and subcellular localization. Firstly, GSK-3 $\beta$ binds to SNAIL and phosphorylates SNAIL at motif 2, which induces the nuclear export of SNAIL. Later, the phosphorylation at motif 1 promotes the ubiquitin-mediated proteasome degradation of SNAIL by $\beta$-Trcp. The inhibition of GSK-3 $\beta$ results in the upregulation of SNAIL and downregulation of E-cadherin that results in the activation of the EMT program [106]. SNAIL activity can also be regulated by phosphorylation on Ser11. This residue is located within the SNAG 


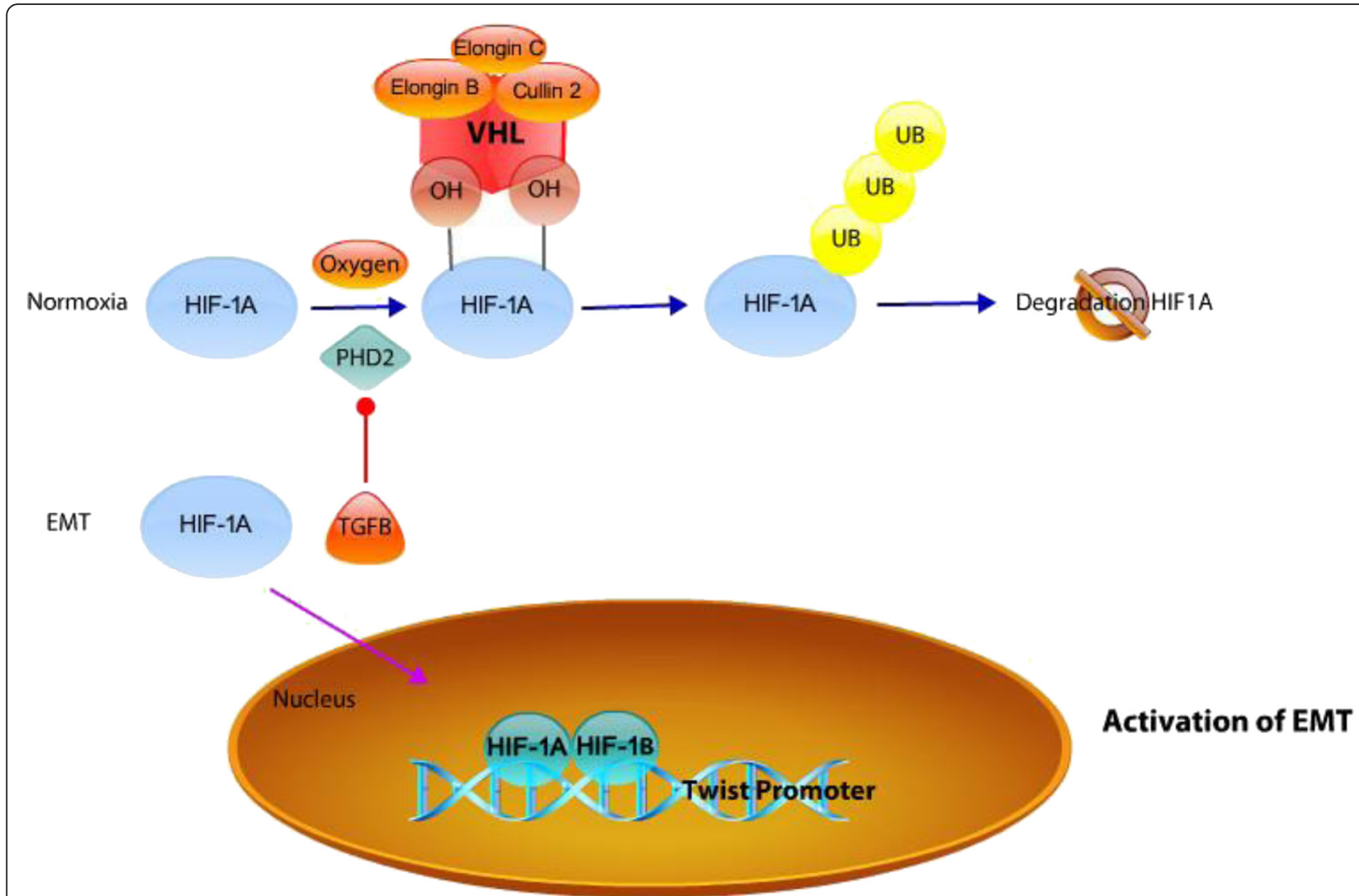

Fig. 2 Hydroxylation of HIF1A. In the presence of oxygen, HIF-1a is hydroxylated by PHD2. This hydroxylation is recognized by a protein complex containing Cullin 2, VHL, Elongin B, and Elongin C that targets HIF-1a for ubiquitination and leads to proteasome degradation of HIF1a. During EMT, the activation of TGF $\beta$ decreases transcription of PHD2, which leads to the stabilization of HIF-1a. The stabilized HIF-1a binds to the hypoxia-response element (HRE) of the TWIST promoter along with HIF-1 $\beta$ to induce its transcription. (Blue arrowhead indicates sequential patterns. indicates inhibition. Purple arrowhead indicates translocation.)

domain that corresponds to the SNAIL transcriptional repression domain. In prostate cancer, the protein kinase D1 (PKD1) acts as a regulator of EMT. PKD1 mediates the phosphorylation at Ser11 of SNAIL. Once phosphorylated, $14-3-3 \sigma$ binds to SNAIL and SNAIL can no longer function on E-cadherin [107]. These results suggest that PKD1 acts as a tumor and metastasis suppressor as it regulates Snail-mediated EMT. Furthermore, phosphorylation at Ser 11 of SNAIL mediated by PKD1 serves as a binding site for FBXO11, an E3 ligase that promotes SNAIL ubiquitination and degradation [108]. These results establish a mechanism of post translational regulation of EMT mediated by the PKD1-FBXO11-SNAIL axis (Fig. 3a).

Several tyrosine kinase receptors can also activate EMT. Epidermal Growth Factor Receptor (EGFR) is a transmembrane glycoprotein with an intracellular protein tyrosine kinase domain. The activation of EGFR by EGF, results in the activation of multiple pathways including ERK-1/2, PI3K and Stat3 via phosphorylation [109]. The overexpression of EGFR is associated with tumor progression and poor prognosis [110]. Lu and colleagues showed that the treatment of cancer cells that overexpress EGFR with EGF increased cell motility and invasion by the rapid dephosphorylation of focal adhesion kinase (FAK). Tumor cells with inactive FAK are less adherent to the extracellular matrix (ECM), which promotes cell motility, invasion, and metastasis [110]. The disassembly of tight junctions during EMT can occur in a SMAD independent manner as well. TGFßRI and Par6 coexist in the tight junctions. Upon stimulation of TGF $\beta$, the T $\beta$ RI- T $\beta$ RII hetero-dimerize, resulting in a complex containing T $\beta R I I / T \beta R I$ and Par6 in each tight junction. This interaction results in phosphorylation of Par6 at Ser345, which is mediated by TßRII [111]. Phosphorylated Par6 interacts with the E3-ubiquitin ligase Smurf-1 that targets RhoA for degradation, leading to the disassembly of tight junctions (Fig. 3b). Thus TGF- beta signaling has good therapeutic value $[112,113]$.

Although aberrant phosphorylation of multiple proteins in different pathways is a major event during cancer development and progression, the design of viable therapeutic targets that inhibit this event seems 
A

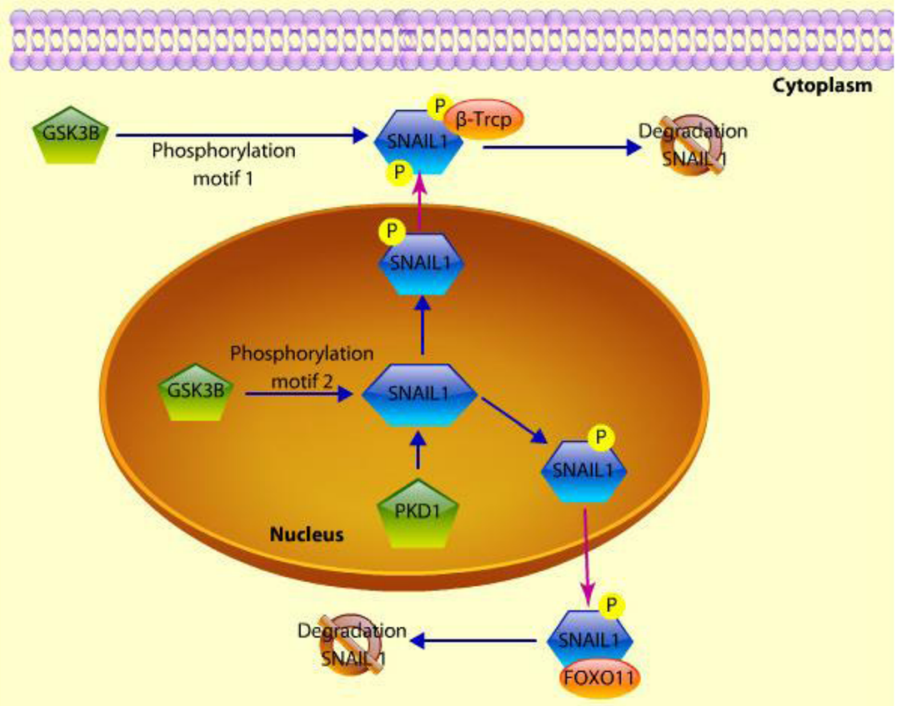

B

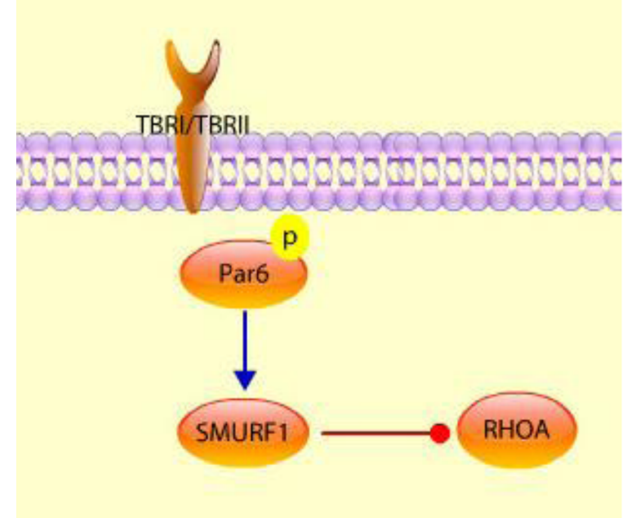

Fig. 3 Phosphorylation of SNAIL and Par6. (Blue arrowhead indicates sequential patterns. indicates inhibition. Purple arrowhead indicates translocation.) a. SNAIL phosphorylation that suppresses EMT. GSK-3 $\beta$ phosphorylates SNAIL at two consecutive motifs. First, the phosphorylation at the second motif induces the cytoplasmic translocation of SNAIL from the nucleus. In the cytoplasm, SNAIL is phosphorylated on motif 1, and this phosphorylation is recognized by $\beta$-Trcp which targets it for proteosomal degradation of SNAIL. PKD1 is another kinase that phosphorylates SNAIL so it can be recognized by $\beta$-Trcp and FOXO11 that target it for proteosomal degradation. b. Mechanisms of EMT activation mediated by TGF $\beta$ R. The activation of TGF $\beta$ R results in the phosphorylation of Par6, and in turn activation of SMURF1 that targets RHOA degradation by the proteasome, which contributes to the disassembly of the tight junctions

challenging and the consequences may not be beneficial in all carcinomas. For example, phosphorylation of SNAIL mediated either by PKD1 or GSK-3 $\beta$ results in SNAIL degradation by the proteasome. This suggests that a good therapeutic target would be to induce the expression of GSK-3 $\beta$ to promote SNAIL degradation by the proteasome, which would in turn inhibit EMT. However, the inhibition of GSK-3 $\beta$ is also a viable therapeutic target [114]. As mentioned above, the design of therapeutic targets in cancer should be done with caution because many proteins can have dual functions as "suppressors" or "oncogenes" as in the case of GSK-3 $\beta$ and TGF $\beta$ whose biological effects may be different.

\section{SUMOylation}

SUMOylation is another post-translational modification characterized by the reversible binding of Small Ubiquitin-like MOdifier (SUMO) to the target protein. The three-dimensional structure of SUMO is similar to ubiquitin $[115,116]$. The SUMOylation of a target protein is mediated by a cascade of reactions involving an activating enzyme (e.g., SAE1/2), E2-conjugating enzyme (e.g., UBC9), and an E3 ligase. SUMO groups can be deconjugated by a group of Sentrin/SUMO-specific proteases (SENP) [116].
Forkhead box protein M1(FoxM1) is a transcription factor that belongs to a large family of forkhead box (Fox) transcription factors, which are characterized by the presence of a DNA-binding domain called the forkhead box or winged helix domain [117]. FoxM1 is expressed in proliferating cells and plays an important role in cell cycle progression stimulating the expression of genes involved in $\mathrm{G}_{1}-\mathrm{S}$ and $\mathrm{G}_{2}-\mathrm{M}$ progression [118]. It has been shown that FoxM1 is highly expressed in breast cancer [119]. FoxM1 can promote EMT through its direct binding at the SLUG promoter [120]. FoxM1 is subject to SUMOylation at lysine 463 and this posttranslational modification is required for the full repression of $\mathrm{miR}-200 \mathrm{~b} / \mathrm{c}$ in breast cancer cells [121]. Members of the miR-200 family act as tumor suppressive miRNAs, enhancing the expression of E-cadherin and suppressing the expression of ZEB1 and ZEB2. Thus, the overexpression of miR-200 results in a reduced expression of ZEB transcription factors and enhanced expression of epithelial makers [121-123]. In pancreatic cancer, FoxM1 is overexpressed and promotes EMT by the up-regulation of mesenchymal cell markers such as ZEB1, ZEB2, SLUG, and vimentin [117] (Fig. 4a).

The transcription factor activator protein 2C (TFAP2C) is very important in breast cancer biology, especially in luminal subtypes as it regulates genes including estrogen 


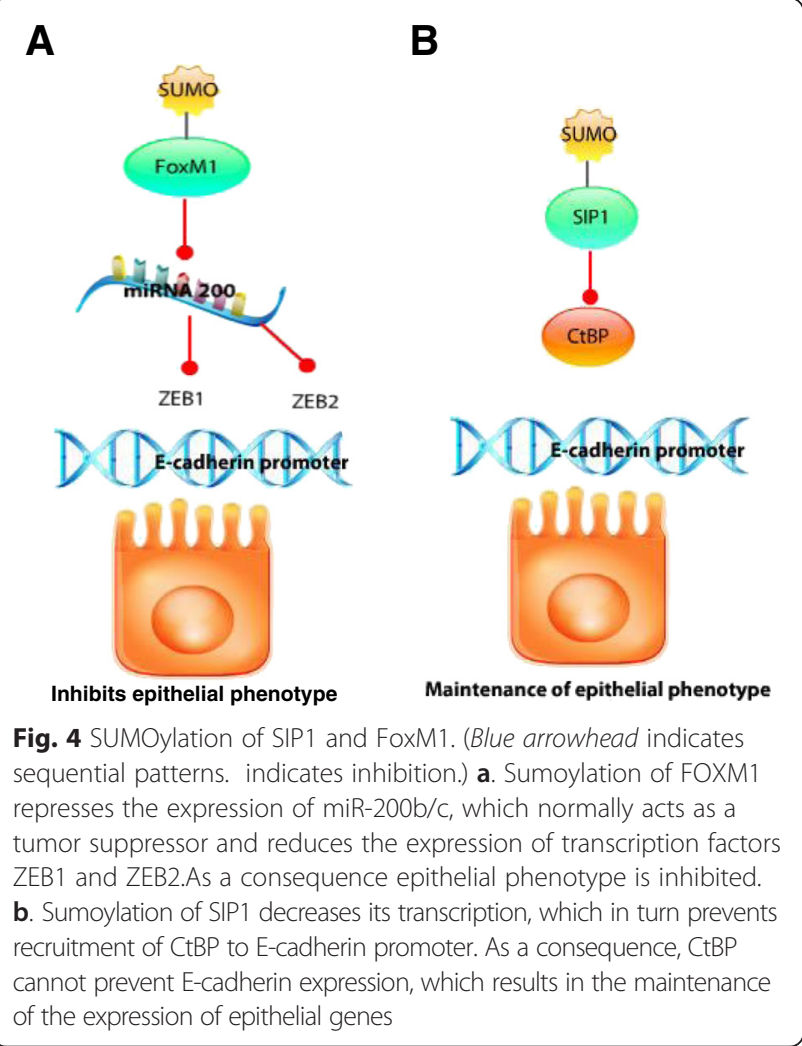

receptor-alpha (ER $\alpha)$ and HER2/c-erbB2. The expression of TFAP2C is critical for maintaining the luminal phenotype of breast cancer cells. The loss of TFAP2C in luminal breast cancer cell lines induces luminal to basal transition accompanied by an increase in the expression of mesenchymal markers (Vimentin and N-cadherin) and loss of E-cadherin. These results suggest that TFAP2C plays an important role in the regulation of luminal-specific genes [124]. TFAP2C undergoes SUMOylation that blocks its ability to induce the expression of luminal genes and helps it to maintain basal like features. The disruption of SUMOylation of TFAP2A induces a basal-to-luminal transition [125]. Although this mechanism is not directly related to EMT, it shows evidence of a transition to a more aggressive intrinsic subtype of breast cancer which as mentioned before, is characterized by high expression of mesenchymal genes.

Smad-Interacting Protein 1 (SIP1) is a member of the zfh-1 family and plays important functions during embryonic development. SIP1 has a binding motif for the corepressor C-terminal-binding protein (CtBP). SIP1 can induce EMT through the recruitment of CtBP to the CDH1 promoter to repress its transcription. SIP1 is a target for SUMOylation mediated by the polycomb protein Pc2. This post- translational modification attenuates transcription of SIP1 and disrupts the recruitment of the corepressor CtBP. As a consequence, CDH1 expression is maintained [126] (Fig. 4b). One of the mechanisms by which TGF $\beta$ regulates EMT is by the downregulation of the PIAS1 (protein inhibitor of activated STAT) which is a SUMO E3 ligase $[127,128]$. It has been shown that the activation of PIAS1 suppresses the ability of TGF $\beta$ to activate matrix metalloproteinase 2 (MMP2) and invasive properties of breast cancer cells. In vivo, the disruption of the activity of PIAS1 in MDA-MB-231, enhance the development of bone metastasis after intracardiac injections of the cancer cells [127]. These results suggest that PIAS1 suppresses breast cancer metastasis through the inhibition of TGF $\beta$.

SUMOylation plays an important role in the regulation of gene expression, genome instability, cellular functions, cellular senescence and stem cell reprogramming [129]. Furthermore, several investigators linked SUMO modification to other important diseases such as neurodegenerative disorders and heart diseases [130-133]. The addition of SUMO groups to transcription factors usually results in a decrease of gene expression of the target gene, which in turn results in the repression of Ecadherin and activation of mesenchymal genes.

\section{Glycosylation}

The $O$-linked $\beta$ - $N$-acetylglucosamine $(O-G l c N A c)$ modification is a monosaccharide addition that occurs in nuclear and cytoplasmic proteins such as transcription factors, cytoskeletal proteins, nuclear pore proteins, oncogenes, and tumor suppressors specifically on serine (Ser) or threonine (Thr) residues. The uridine 5'-diphospho-Nacetylglucosamine (UDP-GlcNAc) is transferred to serine or threonine residues by the O-GlcNAc transferase (OGT) to produce the O-GlcNAc modification, while the removal of the modification is performed by an OGlcNAcase [134, 135].

In signal transduction cascades, the O-GlcNAcylation interplays with $\mathrm{O}$-phosphorylation to regulate the function of several proteins $[134,136]$. The inhibition of GSK3 $\beta$ results in the increase of O-GlcNAcylation of proteins including heat shock proteins, tubulin beta and vimentin; and at the same time decreases this modification on other proteins such as members of the hnRNP superfamily [136]. SNAIL is subject to O-GlcNAc at Ser 112 under hyperglycemic conditions. This modification leads to stabilization of SNAIL by inhibition of its O-phosphorylation, which is mediated by GSK3 $\beta$. Consequently, the O-GlcNAc SNAIL promotes EMT [134] (Fig. 5). As discussed, EMT occurs due to the downregulation of epithelial markers and upregulation of mesenchymal markers such as vimentin, $\mathrm{N}$-cadherin and fibronectin [137]. Oncofetal fibronectin (onfFN) is expressed in cancer or fetal cells/tissues, but not in normal adult cells/tissues and can be identified using mouse mAb FDC6. This antibody reacts with a specific O-glycosylated peptide sequence in IIICS domain of 

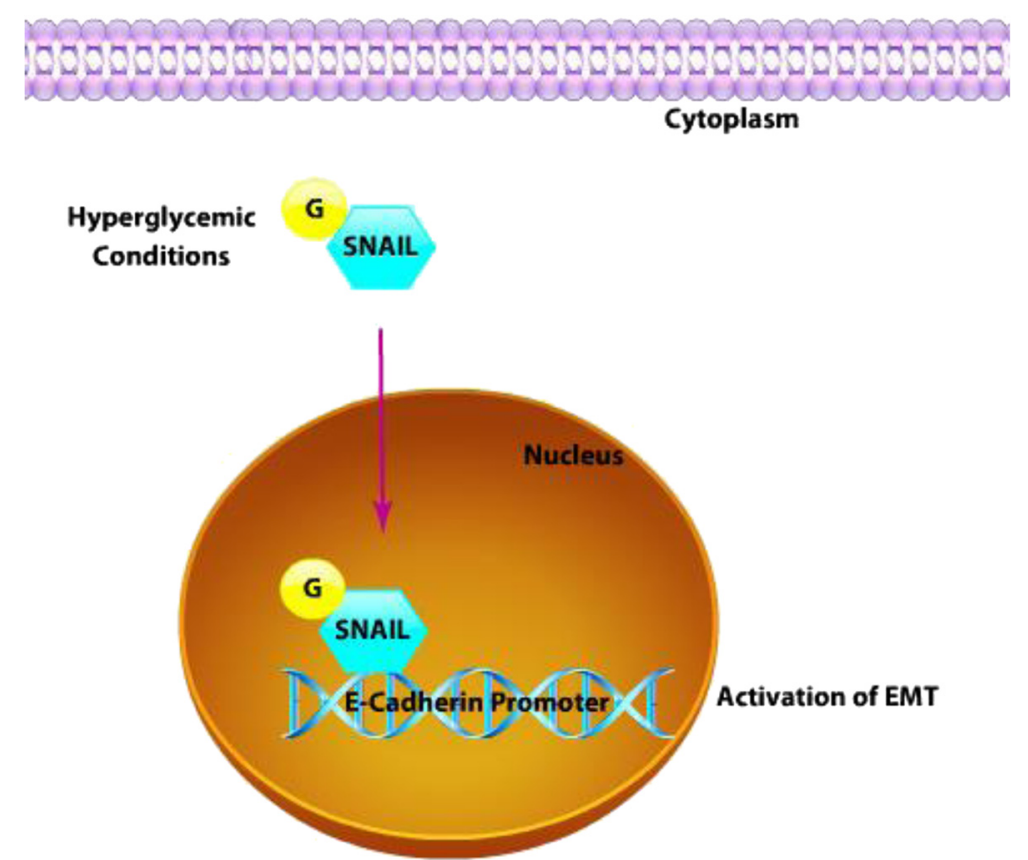

Fig. 5 SNAIL Glycosylation. SNAIL is subject to O-linked glycosylation under hyperglycemic conditions. Consequently, the O-GIcNAc SNAIL promotes EMT by translocating it to the nucleus to bind to the E-cadherin promoter. (Purple arrowhead indicates translocation.)

onfFN. It has been shown that the treatment with TGF $\beta$ in human prostate epithelial cell lines, induces the addition of O-glycan at a specific threonine at the type III homology connective segment (IIICS) domain of FN which is associated with the change in the morphology of the epithelial cells to fibroblast morphology, decrease of epithelial markers and an increase in the motility of these cells. The knockdown of this modification inhibits the TGF- $\beta$-induced up-regulation of onfFN and EMT process [138]. SNAIL is regulated by phosphorylation as well as glycosylation. Phosphorylation of SNAIL promotes its degradation. Oppositely, glycosylation of SNAIL stabilizes the protein under conditions of hypoglycemia. This raises one interesting question regarding the effect of glycosylation of SNAIL in normoglycemic conditions. It remains unclear what effect glycosylation of SNAIL has in cancer.

\section{Conclusion}

Approximately $90 \%$ of cancer mortalities occur in patients with tumors derived from epithelial tissues, and the primary cause of death in such cases results from dissemination of tumor cells to distant organs [139]. As such, understanding the cellular mechanisms contributing to metastasis is paramount in the effort to improve outcomes. EMT is a process in which tumor cells within the primary tumor lose their cell junctions and their epithelial morphology changes to fibroblastoid morphology.
These changes allow the cells to invade the surrounding tissue of the primary tumor, intravasate into the bloodstream and lymphatic vessels as circulating tumor cells (CTC), and extravasate to distant sites where they may colonize distant organs as epithelial metastasis. Although EMT is a process that occurs under normal conditions such as wound healing and embryogenesis, the misappropriation of these pathways during tumor progression is an unpredictable and disastrous event with the simultaneous activation of different molecular cascades.

Many pharmacological approaches, including chemical inhibitors and monoclonal antibodies that target several proteins that regulate cancer progression have been devised and show promising results for the treatment of a variety of cancers. However, very little research has been done to target post translational modifications of proteins in cancers, and thus we believe that identifying inhibitors for post-translational modifications represents an underexplored area which may hold significant potential, and thus should be a high priority in the development of future cancer treatments. Furthermore, the identification of these post-transcriptional and posttranslational modifications is important given that these changes could be identified in the primary tumor before metastasis occurs. Such knowledge would allow clinicians to better predict which patients have genotypes more likely to follow an aggressive clinical course prone to development of metastases. These patients could then 
be treated with different approaches from the onset of disease to reduce the risk of metastasis, and allow for better prognoses and ultimately, enhance survival.

\section{Competing interestss}

The authors declare that they have no competing interests.

\section{Authors' contributions}

SA conceptualized, SG wrote, and SA, MM and SG finalized the manuscript together. All authors read and approved the final manuscript.

\section{Acknowledgments}

We would like to thank our lab colleague, Steven Eastlack for critical reading of the manuscript. We apologize to several investigators whose outstanding work could not be cited.

\section{Author details}

'Department of Biochemistry and Molecular Biology, LSUHSC School of Medicine, New Orleans, LA 70112, USA. ²Pontificia Universidad Javeriana, Bogota, Colombia.

\section{Received: 21 August 2015 Accepted: 13 February 2016}

Published online: 24 February 2016

\section{References}

1. Radisky DC. Epithelial-mesenchymal transition. J Cell Sci. 2005;118:4325-6.

2. Thiery JP, Acloque H, Huang RY, Nieto MA. Epithelial-mesenchymal transitions in development and disease. Cell. 2009;139:871-90.

3. Lee JM, Dedhar S, Kalluri R, Thompson EW. The epithelial-mesenchymal transition: new insights in signaling, development, and disease. J Cell Biol. 2006;172:973-81.

4. Kalluri R. EMT: when epithelial cells decide to become mesenchymal-like cells. J Clin Invest. 2009;119:1417-9.

5. Varga J, De Oliveira T, Greten FR. The architect who never sleeps: tumorinduced plasticity. FEBS Lett. 2014;588:2422-7.

6. Kalluri $\mathrm{R}$, Weinberg RA. The basics of epithelial-mesenchymal transition. J Clin Invest. 2009;119:1420-8.

7. De Craene B, Berx G. Regulatory networks defining EMT during cancer initiation and progression. Nat Rev Cancer. 2013;13:97-110.

8. Huang RY, Guilford P, Thiery JP. Early events in cell adhesion and polarity during epithelial-mesenchymal transition. J Cell Sci. 2012;125:4417-22.

9. Wells A, Chao YL, Grahovac J, Wu Q, Lauffenburger DA. Epithelial and mesenchymal phenotypic switchings modulate cell motility in metastasis. Front Biosci (Landmark Ed). 2011;16:815-37.

10. Puisieux A, Brabletz T, Caramel J. Oncogenic roles of EMT-inducing transcription factors. Nat Cell Biol. 2014;16:488-94.

11. Grunert $\mathrm{S}$, Jechlinger $\mathrm{M}$, Beug $\mathrm{H}$. Diverse cellular and molecular mechanisms contribute to epithelial plasticity and metastasis. Nat Rev Mol Cell Biol. 2003;4: 657-65.

12. Micalizzi DS, Farabaugh SM, Ford HL. Epithelial-mesenchymal transition in cancer: parallels between normal development and tumor progression. J Mammary Gland Biol Neoplasia. 2010;15:117-34.

13. Gonzalez DM, Medici D. Signaling mechanisms of the epithelialmesenchymal transition. Sci Signal. 2014;7:re8.

14. Kang Y, Massague J. Epithelial-mesenchymal transitions: twist in development and metastasis. Cell. 2004:118:277-9.

15. Yang J, Weinberg RA. Epithelial-mesenchymal transition: at the crossroads of development and tumor metastasis. Dev Cell. 2008:14:818-29.

16. Cordonnier T, Bishop JL, Shiota M, Nip KM, Thaper D, Vahid S, et al. Hsp27 regulates EGF/beta-catenin mediated epithelial to mesenchymal transition in prostate cancer. Int J Cancer. 2015;136:E496-507.

17. Nieto MA. Epithelial plasticity: a common theme in embryonic and cance cells. Science 2013:342:1234850.

18. Bill R, Christofori $G$. The relevance of EMT in breast cancer metastasis: Correlation or causality? FEBS Lett. 2015:589:1577-87.

19. Lamouille S, Xu J, Derynck R. Molecular mechanisms of epithelialmesenchymal transition. Nat Rev Mol Cell Biol. 2014;15:178-96.

20. Labelle M, Begum S, Hynes RO. Direct signaling between platelets and cancer cells induces an epithelial-mesenchymal-like transition and promotes metastasis. Cancer Cell. 2011;20:576-90.
21. Moreno-Bueno G, Portillo F, Cano A. Transcriptional regulation of cell polarity in EMT and cancer. Oncogene. 2008:27:6958-69.

22. Kouzarides T. Chromatin modifications and their function. Cell. 2007;128:693-705.

23. Walsh CT, Garneau-Tsodikova S, Gatto Jr GJ. Protein posttranslational modifications: the chemistry of proteome diversifications. Angew Chem Int Ed Engl. 2005:44:7342-72.

24. Wu CY, Tsai YP, Wu MZ, Teng SC, Wu KJ. Epigenetic reprogramming and post-transcriptional regulation during the epithelial-mesenchymal transition. Trends Genet. 2012;28:454-63.

25. Hudlebusch HR, Santoni-Rugiu E, Simon R, Ralfkiaer E, Rossing HH, Johansen JV, et al. The histone methyltransferase and putative oncoprotein MMSET is overexpressed in a large variety of human tumors. Clin Cancer Res. 2011:17:2919-33.

26. Baranwal S, Alahari SK. Molecular mechanisms controlling E-cadherin expression in breast cancer. Biochem Biophys Res Commun. 2009:384: $6-11$

27. Chen A, Beetham H, Black MA, Priya R, Telford BJ, Guest J, et al. E-cadherin loss alters cytoskeletal organization and adhesion in non-malignant breast cells but is insufficient to induce an epithelial-mesenchymal transition. BMC Cancer. 2014;14:552

28. Acs G, Lawton TJ, Rebbeck TR, LiVolsi VA, Zhang PJ. Differential expression of E-cadherin in lobular and ductal neoplasms of the breast and its biologic and diagnostic implications. Am J Clin Pathol. 2001;115:85-98.

29. Pharoah PDP, Guilford P, Caldas C. Incidence of gastric cancer and breast cancer in $\mathrm{CDH} 1$ (E-cadherin) mutation carriers from hereditary diffuse gastric cancer families. Gastroenterology. 2001;121:1348-53.

30. Guilford P, Hopkins J, Harraway J, McLeod M, McLeod N, Harawira P, et al. E-cadherin germline mutations in familial gastric cancer. Nature. 1998:392:402-5.

31. Peinado $\mathrm{H}$, Ballestar E, Esteller M, Cano A. Snail mediates E-cadherin repression by the recruitment of the $\operatorname{Sin} 3 \mathrm{~A} /$ histone deacetylase 1 (HDAC1)/ HDAC2 complex. Mol Cell Biol. 2004:24:306-19.

32. Yoshiura K, Kanai $Y$, Ochiai A, Shimoyama Y, Sugimura T, Hirohashi S. Silencing of the E-cadherin invasion-suppressor gene by CpG methylation in human carcinomas. Proc Natl Acad Sci U S A. 1995;92: 7416-9.

33. Bolos V, Peinado H, Perez-Moreno MA, Fraga MF, Esteller M, Cano A. The transcription factor Slug represses E-cadherin expression and induces epithelial to mesenchymal transitions: a comparison with Snail and E47 repressors. J Cell Sci. 2003;116:499-511.

34. Canel M, Serrels A, Frame MC, Brunton VG. E-cadherin-integrin crosstalk in cancer invasion and metastasis. J Cell Sci. 2013;126:393-401.

35. Vesuna $F$, van Diest $P, C$ hen $J H$, Raman $V$. Twist is a transcriptional repressor of E-cadherin gene expression in breast cancer. Biochem Biophys Res Commun. 2008:367:235-41.

36. Cedar H, Bergman Y. Linking DNA methylation and histone modification: patterns and paradigms. Nat Rev Genet. 2009:10:295-304.

37. Lin Y, Dong C, Zhou BP. Epigenetic regulation of EMT: the Snail story. Curr Pharm Des. 2014:20:1698-705.

38. Fukagawa A, Ishii H, Miyazawa K, Saitoh M. deltaEF1 associates with DNMT1 and maintains DNA methylation of the E-cadherin promoter in breast cancer cells. Cancer Med. 2015;4:125-35.

39. Subramaniam D, Thombre R, Dhar A, Anant S. DNA methyltransferases: a novel target for prevention and therapy. Front Oncol. 2014;4:80.

40. Graff JR, Herman JG, Lapidus RG, Chopra H, Xu R, Jarrard DF, et al. Ecadherin expression is silenced by DNA hypermethylation in human breast and prostate carcinomas. Cancer Res. 1995:55:5195-9.

41. Bornman DM, Mathew S, Alsruhe J, Herman JG, Gabrielson E. Methylation of the E-cadherin gene in bladder neoplasia and in normal urothelia epithelium from elderly individuals. Am J Pathol. 2001;159:831-5.

42. Tamura G, Yin J, Wang S, Fleisher AS, Zou T, Abraham JM, et al. E-Cadherin gene promoter hypermethylation in primary human gastric carcinomas. J Natl Cancer Inst. 2000;92:569-73.

43. Lombaerts $M$, van Wezel T, Philippo K, Dierssen JW, Zimmerman RM, Oosting J, et al. E-cadherin transcriptional downregulation by promoter methylation but not mutation is related to epithelial-to-mesenchymal transition in breast cancer cell lines. Br J Cancer. 2006:94:661-71.

44. Oft M, Peli J, Rudaz C, Schwarz H, Beug H, Reichmann E. TGF-beta1 and HaRas collaborate in modulating the phenotypic plasticity and invasiveness of epithelial tumor cells. Genes Dev. 1996;10:2462-77. 
45. Dumont N, Wilson MB, Crawford YG, Reynolds PA, Sigaroudinia M, Tlsty TD. Sustained induction of epithelial to mesenchymal transition activates DNA methylation of genes silenced in basal-like breast cancers. Proc Natl Acad Sci U S A. 2008;105:14867-72.

46. Sanchez-Tillo E, Lazaro A, Torrent R, Cuatrecasas M, Vaquero EC, Castells $A$, et al. ZEB1 represses E-cadherin and induces an EMT by recruiting the SWI/SNF chromatin-remodeling protein BRG1. Oncogene. 2010;29: 3490-500.

47. Sarrio D, Rodriguez-Pinilla SM, Hardisson D, Cano A, Moreno-Bueno G, Palacios J. Epithelial-mesenchymal transition in breast cancer relates to the basal-like phenotype. Cancer Res. 2008;68:989-97.

48. McDonald OG, Wu H, Timp W, Doi A, Feinberg AP. Genome-scale epigenetic reprogramming during epithelial-to-mesenchymal transition. Nat Struct Mol Biol. 2011;18:867-74.

49. Momparler RL. Epigenetic therapy of cancer with 5-aza-2'-deoxycytidine (decitabine). Semin Oncol. 2005;32:443-51.

50. Ateeg B, Unterberger A, Szyf M, Rabbani SA. Pharmacological inhibition of DNA methylation induces proinvasive and prometastatic genes in vitro and in vivo. Neoplasia. 2008;10:266-78.

51. Agathanggelou A, Honorio S, Macartney DP, Martinez A, Dallol A, Rader J, et al. Methylation associated inactivation of RASSF1A from region 3p21.3 in lung, breast and ovarian tumours. Oncogene. 2001;20:1509-18.

52. Moody SE, Perez D, Pan TC, Sarkisian CJ, Portocarrero CP, Sterner CJ, et al. The transcriptional repressor Snail promotes mammary tumor recurrence. Cancer Cell. 2005:8:197-209.

53. Batlle E, Sancho E, Franci C, Dominguez D, Monfar M, Baulida J, et al. The transcription factor snail is a repressor of E-cadherin gene expression in epithelial tumour cells. Nat Cell Biol. 2000;2:84-9.

54. Hubner MR, Spector DL. Role of H3K27 demethylases Jmjd3 and UTX in transcriptional regulation. Cold Spring Harb Symp Quant Biol. 2010;75:43-9.

55. Swigut T, Wysocka J. H3K27 demethylases, at long last. Cell. 2007;131:29-32.

56. Xiang $Y$, Zhu Z, Han G, Lin H, Xu L, Chen CD. JMJD3 is a histone H3K27 demethylase. Cell Res. 2007;17:850-7.

57. Ramadoss S, Chen X, Wang CY. Histone demethylase KDM6B promotes epithelial-mesenchymal transition. J Biol Chem. 2012;287:44508-17.

58. Yang MH, Wu KJ. TWIST activation by hypoxia inducible factor-1 (HIF-1): implications in metastasis and development. Cell Cycle. 2008;7:2090-6.

59. Yang F, Sun L, Li Q, Han X, Lei L, Zhang H, et al. SET8 promotes epithelialmesenchymal transition and confers TWIST dual transcriptional activities. EMBO J. 2012;31:110-23.

60. Yang J, Mani SA, Donaher JL, Ramaswamy S, Itzykson RA, Come C, et al. Twist, a master regulator of morphogenesis, plays an essential role in tumor metastasis. Cell. 2004;117:927-39.

61. Yang J, Mani SA, Weinberg RA. Exploring a new twist on tumor metastasis Cancer Res. 2006;66:4549-52.

62. Ezponda T, Popovic R, Shah MY, Martinez-Garcia E, Zheng Y, Min DJ, et al. The histone methyltransferase MMSET/WHSC1 activates TWIST1 to promote an epithelial-mesenchymal transition and invasive properties of prostate cancer. Oncogene. 2013:32:2882-90.

63. Kassambara A, Klein B, Moreaux J. MMSET is overexpressed in cancers: link with tumor aggressiveness. Biochem Biophys Res Commun. 2009; 379:840-5.

64. Lin Y, Wu Y, Li J, Dong C, Ye X, Chi Yl, et al. The SNAG domain of Snail1 functions as a molecular hook for recruiting lysine-specific demethylase 1. EMBO J. 2010;29:1803-16.

65. Lin T, Ponn A, Hu X, Law BK, Lu J. Requirement of the histone demethylase LSD1 in Snai1-mediated transcriptional repression during epithelialmesenchymal transition. Oncogene. 2010;29:4896-904.

66. Dong $C$, Wu $Y$, Wang $Y$, Wang $C$, Kang T, Rychahou PG, et al. Interaction with Suv39H1 is critical for Snail-mediated E-cadherin repression in breast cancer. Oncogene. 2013;32:1351-62.

67. Nishioka K, Rice JC, Sarma K, Erdjument-Bromage H, Werner J, Wang Y, et al. PR-Set7 is a nucleosome-specific methyltransferase that modifies lysine 20 of histone $\mathrm{H} 4$ and is associated with silent chromatin. Mol Cell. 2002;9:1201-13.

68. Li Z, Nie F, Wang S, Li L. Histone H4 Lys 20 monomethylation by histone methylase SET8 mediates Wht target gene activation. Proc Natl Acad Sci U S A. 2011;108:3116-23.

69. Jorgensen S, Elvers I, Trelle MB, Menzel T, Eskildsen M, Jensen ON, et al. The histone methyltransferase SET8 is required for S-phase progression. J Cell Biol. 2007;179:1337-45
70. Dong C, Wu Y, Yao J, Wang Y, Yu Y, Rychahou PG, et al. G9a interacts with Snail and is critical for Snail-mediated E-cadherin repression in human breast cancer. J Clin Invest. 2012;122:1469-86.

71. Espada J, Peinado H, Lopez-Serra L, Setien F, Lopez-Serra P, Portela A, et al. Regulation of SNAIL1 and E-cadherin function by DNMT1 in a DNA methylation-independent context. Nucleic Acids Res. 2011;39:9194-205.

72. Kelly TK, De Carvalho DD, Jones PA. Epigenetic modifications as therapeutic targets. Nat Biotechnol. 2010;28:1069-78.

73. Kaminskas E, Farrell AT, Wang YC, Sridhara R, Pazdur R. FDA drug approval summary: azacitidine (5-azacytidine, Vidaza) for injectable suspension. Oncologist. 2005;10:176-82.

74. Dai Y, Faller DV. Transcription Regulation by Class III Histone Deacetylases (HDACs)-Sirtuins. Transl Oncogenomics. 2008;3:53-65.

75. Tam WL, Weinberg RA. The epigenetics of epithelial-mesenchymal plasticity in cancer. Nat Med. 2013:19:1438-49.

76. Jurkin J, Zupkovitz G, Lagger S, Grausenburger R, Hagelkruys A, Kenner L, et al. Distinct and redundant functions of histone deacetylases HDAC1 and HDAC2 in proliferation and tumorigenesis. Cell Cycle. 2011;10:406-12.

77. Rikimaru T, Taketomi A, Yamashita Y, Shirabe K, Hamatsu T, Shimada M, et al. Clinical significance of histone deacetylase 1 expression in patients with hepatocellular carcinoma. Oncology. 2007:72:69-74.

78. Bolden JE, Peart MJ, Johnstone RW. Anticancer activities of histone deacetylase inhibitors. Nat Rev Drug Discov. 2006;5:769-84.

79. Lei W, Zhang K, Pan X, Hu Y, Wang D, Yuan X, et al. Histone deacetylase 1 is required for transforming growth factor-beta1-induced epithelialmesenchymal transition. Int J Biochem Cell Biol. 2010;42:1489-97.

80. Aghdassi A, Sendler M, Guenther A, Mayerle J, Behn CO, Heidecke CD, et al. Recruitment of histone deacetylases HDAC1 and HDAC2 by the transcriptional repressor ZEB1 downregulates E-cadherin expression in pancreatic cancer. Gut. 2012;61:439-48.

81. Adhikary A, Chakraborty S, Mazumdar M, Ghosh S, Mukherjee S, Manna A, et al. Inhibition of epithelial to mesenchymal transition by E-cadherin upregulation via repression of slug transcription and inhibition of E-cadherin degradation: dual role of scaffold/matrix attachment region-binding protein 1 (SMAR1) in breast cancer cells. J Biol Chem. 2014;289:25431-44.

82. Fu J, Qin L, He T, Qin J, Hong J, Wong J, et al. The TWIST/Mi2/NuRD protein complex and its essential role in cancer metastasis. Cell Res. 2011;21:275-89.

83. Liu T, Liu PY, Marshall GM. The critical role of the class III histone deacetylase SIRT1 in cancer. Cancer Res. 2009;69:1702-5.

84. Saunders $L R$, Verdin E. Sirtuins: critical regulators at the crossroads between cancer and aging. Oncogene. 2007;26:5489-504.

85. Roth M, Chen WY. Sorting out functions of sirtuins in cancer. Oncogene. 2014;33:1609-20.

86. Huffman DM, Grizzle WE, Bamman MM, Kim JS, Eltoum IA, Elgavish A, et al. SIRT1 is significantly elevated in mouse and human prostate cancer (vol 67, pg 6612, 2007). Cancer Res. 2007;67:8423.

87. Chen $X$, Hokka D, Maniwa Y, Ohbayashi C, Itoh T, Hayashi Y. Sirt1 is a tumor promoter in lung adenocarcinoma. Oncol Lett. 2014;8:387-93.

88. Stenzinger A, Endris V, Klauschen F, Sinn B, Lorenz K, Warth A, et al. High SIRT1 expression is a negative prognosticator in pancreatic ductal adenocarcinoma. BMC Cancer. 2013;13:450.

89. Chen IC, Chiang WF, Huang HH, Chen PF, Shen YY, Chiang HC. Role of SIRT1 in regulation of epithelial-to-mesenchymal transition in oral squamous cell carcinoma metastasis. Mol Cancer. 2014;13:254.

90. Byles V, Zhu L, Lovaas JD, Chmilewski LK, Wang J, Faller DV, et al. SIRT1 induces EMT by cooperating with EMT transcription factors and enhances prostate cancer cell migration and metastasis. Oncogene. 2012;31:4619-29.

91. Lane AA, Chabner BA. Histone deacetylase inhibitors in cancer therapy. J Clin Oncol. 2009;27:5459-68.

92. Wu MZ, Tsai YP, Yang MH, Huang CH, Chang SY, Chang CC, et al. Interplay between HDAC3 and WDR5 is essential for hypoxia-induced epithelialmesenchymal transition. Mol Cell. 2011;43:811-22.

93. Trievel RC, Shilatifard A. WDR5, a complexed protein. Nat Struct Mol Biol. 2009;16:678-80.

94. Chen X, Xiao W, Chen W, Luo L, Ye S, Liu Y. The epigenetic modifier trichostatin $\mathrm{A}$, a histone deacetylase inhibitor, suppresses proliferation and epithelial-mesenchymal transition of lens epithelial cells. Cell Death Dis. 2013:4:e884.

95. Pang M, Zhuang S. Histone deacetylase: a potential therapeutic target for fibrotic disorders. J Pharmacol Exp Ther. 2010;335:266-72. 
96. Stadler SC, Allis CD. Linking epithelial-to-mesenchymal-transition and epigenetic modifications. Semin Cancer Biol. 2012;22:404-10.

97. Tate CR, Rhodes LV, Segar HC, Driver JL, Pounder FN, Burow ME, et al. Targeting triple-negative breast cancer cells with the histone deacetylase inhibitor panobinostat. Breast Cancer Res. 2012;14:R79.

98. Deribe YL, Pawson T, Dikic I. Post-translational modifications in signal integration. Nat Struct Mol Biol. 2010;17:666-72.

99. Pejaver V, Hsu WL, Xin F, Dunker AK, Uversky VN, Radivojac P. The structural and functional signatures of proteins that undergo multiple events of posttranslational modification. Protein Sci. 2014;23:1077-93.

100. Gorres KL, Raines RT. Prolyl 4-hydroxylase. Crit Rev Biochem Mol Biol. 2010; 45:106-24.

101. McMahon S, Charbonneau M, Grandmont S, Richard DE, Dubois CM. Transforming growth factor beta1 induces hypoxia-inducible factor-1 stabilization through selective inhibition of PHD2 expression. J Biol Chem. 2006;281:24171-81.

102. Ubersax JA, Ferrell Jr JE. Mechanisms of specificity in protein phosphorylation. Nat Rev Mol Cell Biol. 2007:8:530-41.

103. Johnson LN. The regulation of protein phosphorylation. Biochem Soc Trans. 2009;37:627-41.

104. Hunter T. Protein kinases and phosphatases: the yin and yang of protein phosphorylation and signaling. Cell. 1995;80:225-36.

105. Saitoh M. Epithelial-mesenchymal transition is regulated at posttranscriptional levels by transforming growth factor-beta signaling during tumor progression. Cancer Sci. 2015;106:481-8.

106. Zhou BP, Deng J, Xia W, Xu J, Li YM, Gunduz M, et al. Dual regulation of Snail by GSK-3beta-mediated phosphorylation in control of epithelialmesenchymal transition. Nat Cell Biol. 2004;6:931-40.

107. Du C, Zhang C, Hassan S, Biswas MH, Balaji KC. Protein kinase D1 suppresses epithelial-to-mesenchymal transition through phosphorylation of snail. Cancer Res. 2010;70:7810-9.

108. Zheng $H$, Shen $M$, Zha YL, Li W, Wei Y, Blanco MA, et al. PKD1 phosphorylation-dependent degradation of SNAIL by SCF-FBXO11 regulates epithelial-mesenchymal transition and metastasis. Cancer Cell. 2014;26:358-73

109. Zuo JH, Zhu W, Li MY, Li XH, Yi H, Zeng GQ, et al. Activation of EGFR promotes squamous carcinoma SCC10A cell migration and invasion via inducing EMT-like phenotype change and MMP-9-mediated degradation of E-cadherin. J Cell Biochem. 2011;112:2508-17.

110. Lu Z, Jiang G, Blume-Jensen $P$, Hunter T. Epidermal growth factor-induced tumor cell invasion and metastasis initiated by dephosphorylation and downregulation of focal adhesion kinase. Mol Cell Biol. 2001;21:4016-31.

111. Ozdamar B, Bose R, Barrios-Rodiles M, Wang HR, Zhang Y, Wrana JL. Regulation of the polarity protein Par6 by TGFbeta receptors controls epithelial cell plasticity. Science. 2005;307:1603-9.

112. Neuzillet C, Tijeras-Raballand A, Cohen R, Cros J, Faivre S, Raymond E, et al. Targeting the TGFbeta pathway for cancer therapy. Pharmacol Ther. 2015; 147:22-31.

113. Zhang B, Halder SK, Zhang S, Datta PK. Targeting transforming growth factor-beta signaling in liver metastasis of colon cancer. Cancer Lett. 2009; 277:114-20.

114. Luo J. Glycogen synthase kinase 3beta (GSK3beta) in tumorigenesis and cancer chemotherapy. Cancer Lett. 2009;273:194-200.

115. Bettermann K, Benesch M, Weis S, Haybaeck J. SUMOylation in carcinogenesis. Cancer Lett. 2012;316:113-25.

116. Bogachek MV, De Andrade JP, Weigel RJ. Regulation of epithelialmesenchymal transition through SUMOylation of transcription factors. Cancer Res. 2015;75:11-5.

117. Bao B, Wang Z, Ali S, Kong D, Banerjee S, Ahmad A, et al. Over-expression of FoxM1 leads to epithelial-mesenchymal transition and cancer stem cell phenotype in pancreatic cancer cells. J Cell Biochem. 2011;112:2296-306.

118. Raychaudhuri P, Park HJ. FoxM1: a master regulator of tumor metastasis. Cancer Res. 2011;71:4329-33.

119. Bektas N, Haaf A, Veeck J, Wild PJ, Luscher-Firzlaff J, Hartmann A, et al. Tight correlation between expression of the Forkhead transcription factor FOXM1 and HER2 in human breast cancer. BMC Cancer. 2008:8:42.

120. Yang C, Chen H, Tan G, Gao W, Cheng L, Jiang X, et al. FOXM1 promotes the epithelial to mesenchymal transition by stimulating the transcription of Slug in human breast cancer. Cancer Lett. 2013;340:104-12.

121. Wang CM, Liu R, Wang L, Nascimento L, Brennan VC, Yang WH. SUMOylation of FOXM1B alters its transcriptional activity on regulation of
MiR-200 family and JNK1 in MCF7 human breast cancer cells. Int J Mol Sci. 2014:15:10233-51.

122. Brabletz S, Brabletz T. The ZEB/miR-200 feedback loop-a motor of cellular plasticity in development and cancer? EMBO Rep. 2010;11:670-7.

123. Hill L, Browne G, Tulchinsky E. ZEB/miR-200 feedback loop: at the crossroads of signal transduction in cancer. Int J Cancer. 2013;132:745-54.

124. Cyr AR, Kulak MV, Park JM, Bogachek MV, Spanheimer PM, Woodfield GW, et al. TFAP2C governs the luminal epithelial phenotype in mammary development and carcinogenesis. Oncogene. 2015;34:436-44.

125. Bogachek MV, Chen Y, Kulak MV, Woodfield GW, Cyr AR, Park JM, et al. Sumoylation pathway is required to maintain the basal breast cancer subtype. Cancer Cell. 2014;25:748-61.

126. Long J, Zuo D, Park M. Pc2-mediated sumoylation of Smad-interacting protein 1 attenuates transcriptional repression of E-cadherin. J Biol Chem. 2005:280:35477-89.

127. Dadakhujaev S, Salazar-Arcila C, Netherton SJ, Chandhoke AS, Singla AK, Jirik FR, et al. A novel role for the SUMO E3 ligase PIAS1 in cancer metastasis. Oncoscience. 2014;1:229-40.

128. Netherton SJ, Bonni S. Suppression of TGFbeta-induced epithelialmesenchymal transition like phenotype by a PIAS1 regulated sumoylation pathway in NMUMG epithelial cells. PLoS One. 2010;5:e13971.

129. Chen Z, Lu W. Roles of ubiquitination and SUMOylation on prostate cancer: mechanisms and clinical implications. Int J Mol Sci. 2015;16:4560-80.

130. Yang XJ, Chiang CM. Sumoylation in gene regulation, human disease, and therapeutic action. F1000Prime Rep. 2013;5:45.

131. Zhao J. Sumoylation regulates diverse biological processes. Cell Mol Life Sci. 2007:64:3017-33.

132. Sarge KD, Park-Sarge OK. Sumoylation and human disease pathogenesis. Trends Biochem Sci. 2009;34:200-5.

133. Baek SH. A novel link between SUMO modification and cancer metastasis. Cell Cycle. 2006;5:1492-5.

134. Park SY, Kim HS, Kim NH, Ji S, Cha SY, Kang JG, et al. Snail1 is stabilized by O-GlcNAc modification in hyperglycaemic condition. EMBO J. 2010;29:3787-96.

135. Wells L, Vosseller K, Hart GW. Glycosylation of nucleocytoplasmic proteins: signal transduction and O-GICNAC. Science. 2001;291:2376-8.

136. Wang Z, Pandey A, Hart GW. Dynamic interplay between O-linked Nacetylglucosaminylation and glycogen synthase kinase-3-dependent phosphorylation. Mol Cell Proteomics. 2007:6:1365-79.

137. Mani SA, Guo W, Liao MJ, Eaton EN, Ayyanan A, Zhou AY, et al. The epithelial-mesenchymal transition generates cells with properties of stem cells. Cell. 2008;133:704-15.

138. Freire-de-Lima L, Gelfenbeyn K, Ding Y, Mandel U, Clausen H, Handa K, et al. Involvement of O-glycosylation defining oncofetal fibronectin in epithelial-mesenchymal transition process. Proc Natl Acad Sci U S A. 2011:108:17690-5.

139. Chaffer CL, Weinberg RA. A perspective on cancer cell metastasis. Science. 2011:331:1559-64

\section{Submit your next manuscript to BioMed Central and we will help you at every step:}

- We accept pre-submission inquiries

- Our selector tool helps you to find the most relevant journal

- We provide round the clock customer support

- Convenient online submission

- Thorough peer review

- Inclusion in PubMed and all major indexing services

- Maximum visibility for your research

Submit your manuscript at www.biomedcentral.com/submit
C Biomed Central 